27. Craven DE, Reed C, Kollisch N, et al. A large outbreak of infections caused by a strain of Staphylococcus aureus resistant to oxacillin and aminoglycosides. Am J Med 1981;71:53-58.

28. Bitar CM, Mayhall CG, Lamb VA, Bradshaw TJ, Spadora AC, Dalton HE Outbreak due to methicillin- and rifampin-resistant Staphylococcus aureus: epidemiology and eradication of the resistant strain from the hospital. Infect Control Hosp Epidemiol $1987 ; 8: 15-23$

29. Linnemann CC, Mason M, Moore P Korfhagen TR, Staneck JL. Methicillin-resistant Staphylococcus aureus: experience in a general hospital over four years. Am J Epidemiol 1982;115:941-950.

30. Murray-Leisure KA, Geib S, Graceley D, et al. Control of epidemic methicillin-resistant Staphylococcus aureus. Infect Control Hosp Epidemiol 1990;11:343-350.

31. Hill RLR, Duckworth GJ, Casewell MW. Elimination of nasal carriage of methicillin-resistant Staphylococcus aureus with mupirocin during a hospital outbreak. J Antimicrob Chemother 1988;22:377-384.

32. Walsh TJ, Vlahov D, Hansen SL, et al. Prospective microbiologic surveillance in control of nosocomial methicillin-resistant Staphy lococcus aureus. Infect Control 1987;8:7-14.

33. Rao N, Jacobs S, Joyce L. Cost-effective eradication of an outbreak of methicillin-resistant Staphylococcus aureus in a community teaching hospital. Infect Control Hasp Epidemiol $1988 ; 9: 255-260$.

34. Goetz AM, Muder RR. The problem of methicillin-resistant Staphylococcus aureus: a critical appraisal of the efficacy of infection control procedures with a suggested approach for infection control programs. Am J Infect Control 1992;84:80-84.

\title{
CDC Reports TB Transmission Between Passengers and Flight Crew on Commercial Aircraft
}

\section{by Gina Pugliese, RN, MS Medical News Editor}

The Centers for Disease Control and Prevention (CDC) recently investigated six instances in which passengers or flight crew traveled on commercial aircraft with symptomatic, AFB smear-positive cavitary tuberculosis (TB). In two instances, Mycobacterium tuberculosis isolated from the index patient was resistant to isoniazid and rifampin. Further, in two instances, the index patients were aware of their TB at the time of travel and were on an international flight in transit to the United States to obtain medical care.

More than 2,000 passengers and flight crew potentially were exposed during these incidents. Follow-up investigation can be difficult because the airlines do not keep addresses of passengers unless they are part of frequent flyer programs.
The CDC concluded that transmission did occur in two of the six investigations, from flight attendant to other flight crew and from passenger to passenger. The cases (tuberculin skin-test conversions) involving flight attendants were associated with cumulative flight time exposure ( $>12$ hours) to an infected flight attendant. All cases involving passengers occurred in passengers seated in the same section of the aircraft as the index passenger, suggesting that transmission was associated with proximity of seating.

The risk for $\mathrm{TB}$ transmission on an aircraft does not appear to be greater than in other confined spaces. Based on current evidence indicating a low risk for transmission of $\mathrm{TB}$ on aircraft, the $\mathrm{CDC}$ recommends that the need for notification of passengers be guided by three criteria: first, whether the person with TB was infectious at the time of the flight; second, whether exposure was prolonged (eg, the duration of the flight exceeded 8 hours); third, priority should be given to notifying passengers and flight crew at greatest risk for exposure, based on proximity to the index case (for example, depending on the aircraft design, proximity may be defined as seating or working in the same cabin section as the infected passenger or crew member).

To prevent exposures to TB aboard an aircraft, the CDC recommends that persons known to have infectious TB should travel by private transportation, not commercial aircraft or other commercial carrier. At a minimum, patients with infectious TB should be sputum smear-negative for AFB before being placed in indoor environments conducive to transmission.

FROM: Centers for Disease Control and Prevention. Exposure of passengers and flight crew to Mycobacterium tuberculosis on commercial aircraft, 1992-1995. M M W R. $1995 ; 44(8): 137-140$ 